Espacio y Desarrollo No 33, 2019, pp. 117-141 (ISSN 1016-9148)

https://doi.org/10.18800/espacioydesarrollo.201901.006

\title{
¿ES POSIBLE UNA MINERÍA AURÍFERA EN PEQUEÑA ESCALA RESPONSABLE CON EL AMBIENTE? IMPACTOS AMBIENTALES Y PERCEPCIÓN EN UNA MICROCUENCA DE LA AMAZONÍA SUR PERUANA
}

\author{
Paola Moschella \\ Pontificia Universidad Católica del Perú \\ pmoschella@pucp.edu.pe
}

Fecha de recepción: 19 de abril 2019

Fecha de aceptación: 24 de mayo 2019

\section{RESUMEN}

Se discute el potencial de desarrollo de la pequeña minería aurífera de manera más responsable con el ambiente, la cual puede convertirse en una estrategia de desarrollo inclusivo en la región Madre de Dios. Con mayor énfasis, se examina la percepción ambiental de la población local en relación con los impactos ambientales de la minería aurífera y la disposición a adoptar medidas de reducción de impactos ambientales. El caso de estudio es la microcuenca Huacamayo, una de las principales zonas mineras de la región Madre de Dios, la cual mostró un acelerado proceso de expansión de esta actividad entre los ańos 2007 y 2009. Los resultados muestran que los principales factores que intervienen en la percepción de los impactos ambientales son la posibilidad de observación directa del impacto, la capacidad de comprensión de las causas y procesos que intervienen, y la disponibilidad de información. La débil apreciación del bosque y de los servicios que ofrece, sumada a la predominancia de la lógica extractivista, han facilitado las prácticas que degradan el ambiente de la microcuenca Huacamayo. En este contexto, la mayor parte de la población identifica los principales impactos de la actividad minera y manifiesta su disposición a adoptar medidas para reducirlos. Se debería aprovechar esta disposición de la población mediante la orientación técnica, los incentivos y los instrumentos de control. Asimismo, es importante promover la revaloración de los servicios ecosistémicos.

Palabras clave: minería aluvial, minería artesanal, percepción ambiental, impacto ambiental, Madre de Dios. 


\section{Is a environment-friendly small-scale gold mining possible? Environmental impacts and perception in a small watershed in the southern Peruvian Amazon}

\section{Abstract}

The potential of an environment-friendly small-scale gold mining is discussed, which can become an inclusive development strategy in the Madre de Dios region. The study focuses on the perception of the local population of the environmental impacts of gold mining and the willingness to adopt measures to reduce those impacts. The case study is the Huacamayo small watershed, one of the main mining areas of the Madre de Dios region, which showed an accelerated process of expansion of this activity between 2007 and 2009. The results show that the main factors involved in the perception of environmental impacts are: the possibility of direct observation of the impact, the ability to understand the causes and processes involved and the availability of information. The weak appreciation of the forest and the services it offers, together with the predominance of an extractivist logic, have facilitated practices that degrade the environment. The majority of the population identifies the main impacts of mining activity and expresses its willingness to adopt measures to reduce them. The disposition of the population should be considered to improve the mining processes through technical guidance, incentives or control mechanisms. Likewise, it is important to promote the appreciation of ecosystem services.

Keywords: alluvial mining, artisanal mining, environmental perception, environmental impact, Madre de Dios.

\section{INTRODUCCIÓN $^{1}$}

La explotación del oro aluvial en la Amazonía sur peruana es conocida por sus múltiples problemas socioambientales, pero, a la vez, reúne características por las que podría considerarse una opción de desarrollo regional si se realiza cumpliendo estándares sociales y ambientales. Para empezar, tiene un potencial de desarrollo inclusivo, ya que la minería artesanal y de pequeña escala, a diferencia de la gran minería, genera mayor empleo directo, no requiere de mano de obra calificada y los ingresos que produce se destinan en gran medida al ámbito local.

Desde un enfoque de aprovechamiento estratégico de los recursos naturales de la región, la minería aurífera aluvial es mucho más rentable que la actividad agropecuaria, causante de la mayor parte de la deforestación de Madre de Dios. Además, actualmente, su generación de empleo excede ampliamente la de actividades más sostenibles, como el turismo y el aprovechamiento forestal. Es claro que la explotación de un recurso no renovable, como lo es el oro, no puede convertirse en una actividad sostenible.

\footnotetext{
1 La presente investigación se realizó gracias a una beca de investigación de Tambopata Reserve Society y al Programa de Apoyo al Desarrollo de Tesis de Licenciatura de la Pontificia Universidad Católica del Perú.
} 
Sin embargo, podría ser conveniente aprovechar los recursos de una pequeña minería bien manejada en el corto o mediano plazo para establecer los medios necesarios que permitan impulsar la actividad forestal y el turismo como bases del desarrollo sostenible e inclusivo de la región en el largo plazo. En ese sentido, Azpur, Baca, Viale y Monge (2011) plantean, desde un enfoque de transición hacia un modelo posextractivista, que el país se beneficie «al máximo de las actividades extractivas que tengan licencia social y viabilidad ambiental. Mientras sentamos las bases de un desarrollo menos dependiente de la extracción de minerales, petróleo y gas; y mientras construimos una cultura y un comportamiento colectivo menos extractivista en general» (Azpur et al., 2011, pp. 27-28).

Por los motivos expuestos, la minería aluvial podría convertirse en una estrategia de desarrollo inclusivo en la región Madre de Dios. Resulta pertinente, por tanto, evaluar la viabilidad de una minería aurífera en pequeña escala responsable con el ambiente. Así, las preguntas que se propone responder el presente ensayo son las siguientes: ¿existen estrategias que permitan reducir los impactos ambientales de la minería aurífera aluvial en la Amazonía? y ¿la población de los asentamientos mineros estaría dispuesta a que se den estos cambios?

Para responder estas preguntas, el análisis se centra en el caso de la microcuenca Huacamayo, una de las principales zonas mineras de la región Madre de Dios, la cual mostró un acelerado proceso de expansión de esta actividad entre los años 2007 y 2009. El estudio se basa en un análisis cualitativo de información a partir de entrevistas, observaciones en campo, revisión bibliográfica y análisis de imágenes satelitales. El trabajo de campo comprendió cuatro viajes entre febrero de 2009 y mayo de 2011.

El estudio de impactos socioambientales de la pequeña minería y la minería artesanal en la región Madre de Dios ha sido abordado por Mosquera, Chávez, Pachas y Moschella (2009), quienes explican los impactos de las distintas formas de extracción minera en la región; mientras que Kahhat, Parodi, Larrea-Gallegos, Mesta y VázquezRowe (2019) analizan los impactos en la toxicidad ambiental y el cambio climático a través del análisis de ciclo de vida. Asimismo, el Instituto de Investigaciones de la Amazonía Peruana y el Ministerio del Ambiente (2011) recopilan los resultados de diversas investigaciones en la región y describen los impactos de la contaminación por mercurio. De manera más específica, el tema del mercurio en la región se ha estudiado en relación con su impacto en la salud humana (Ashe, 2012; Diringer et al., 2015) y en la fauna (Gutleb, Schenck y Staib, 1997; Deza, 1996; Fernández y González, 2019; Kumar, Divoll, Ganguli, Trama y Lamborg, 2018; Moreno-Brush, Portillo, Brändell, Storch, Tschapka y Biester, 2018; Shrum, 2009); así como en relación con la tecnología y el uso del mercurio (Medina, 2007; Neisser, 1995). Asimismo, hay estudios de identificación del área deforestada por la minería en la región (Elmes, Yarlequé Ipanaqué, Rogan, Cuba y Bebbington, 2014; Swenson, Carter, Domec y Delgado, 2011). 
A nivel de toda la Amazonía, Hacon y Azevedo (2006) señalan el aumento de estudios sobre la contaminación con mercurio, sobre todo en Brasil, y el incremento de grupos de investigación interdisciplinarios con enfoque socioecológico y participativo que integran a los actores sociales involucrados en los procesos de contaminación ambiental. Desde el estudio de la percepción, Ayala-Camacho y García-Samaniego (2016) analizan la percepción de la minería artesanal en Ecuador, y Heemskerk (2002) analiza la decisión de participar en la pequeña minería aurífera en Surinam. Por su parte, Salo, Hiedanpää, Karlsson, Ávila, Kotilainen, Jounela y García (2016) estudian la percepción del impacto social de la minería aurífera en Madre de Dios. Sin embargo, no se conocen estudios que profundicen sobre la percepción de los impactos ambientales de la minería aurífera en la Amazonía.

El enfoque del estudio parte de la geografía del comportamiento, la cual sustenta que las acciones sobre el territorio son mediadas por los procesos cognitivos (Argent y Walmsley, 2009; Gold, 1980). La percepción ambiental es considerada de gran importancia en la evaluación de impactos, determinada, en gran parte, por la capacidad de comprender el problema, la posibilidad de medir sus características y la disponibilidad de información (Bernex, 2008). Además, Nickerson (2003) destaca la influencia de factores como la identificación con la causa del problema, las condiciones de calidad ambiental a las que las personas están acostumbradas y el contacto previo con la naturaleza. En este sentido, la evaluación de la viabilidad de una minería aurífera en pequeńa escala responsable con el ambiente requiere incluir la comprensión de la percepción ambiental local y la opinión respecto de las estrategias de mitigación de los impactos ambientales.

\section{El ÁREA DE ESTUdio}

El estudio se centra en la microcuenca Huacamayo, perteneciente a la cuenca del río Inambari, en el distrito Inambari en la provincia de Tambopata, región Madre de Dios. Se trata de una región que ha atraído flujos migratorios desde fines del siglo XIX por actividades primarias, como la extracción de caucho, la actividad agropecuaria a lo largo de la carretera, la extracción de castaña, la búsqueda de petróleo y la extracción de oro desde 1930 (Junquera, 1997; Urteaga, 2003). Desde la década de 1980, incrementa la migración por la minería debido a la promoción de la colonización en la selva (Dourojeanni, 1990), así como al alza del precio del oro, la crisis de la agricultura en la sierra, la falta de empleo y la violencia política (Romero, Pachas, Zambrano y Guarniz, 2005; Urteaga, 2003).

La microcuenca Huacamayo comprende parte del territorio étnico tradicional Harakmbut (Urteaga, 2003), aunque, actualmente, la comunidad nativa más cercana se encuentra a $12 \mathrm{~km}$ de distancia. Forma parte de la llanura recorrida por ríos meándricos 
Figura 1. Mapa del área de estudio

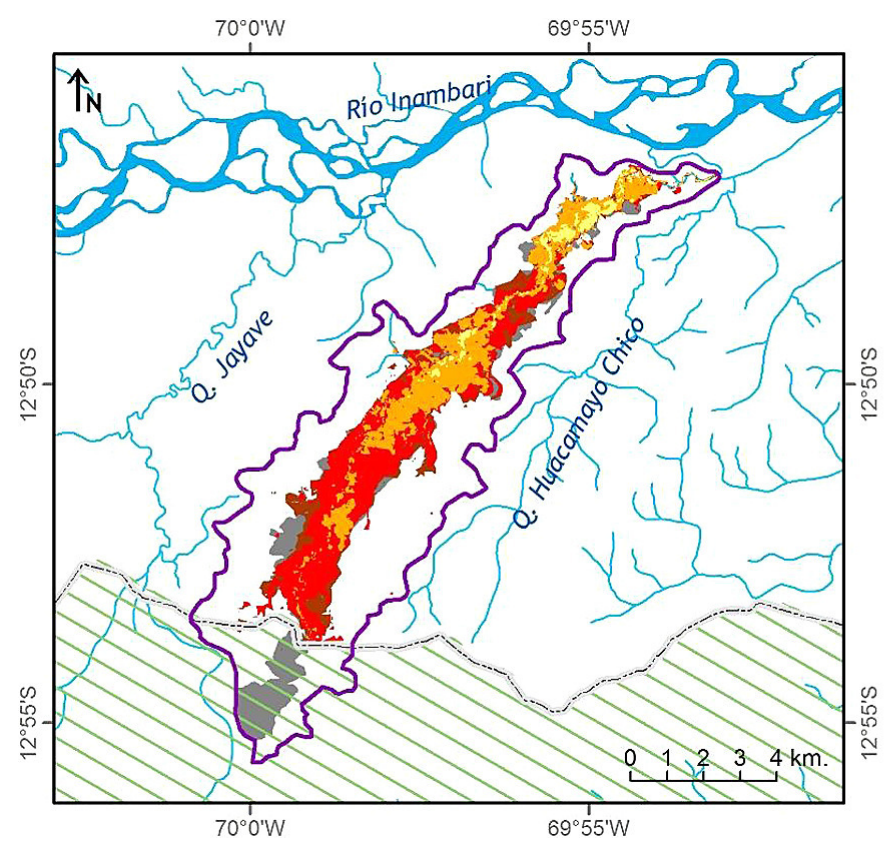

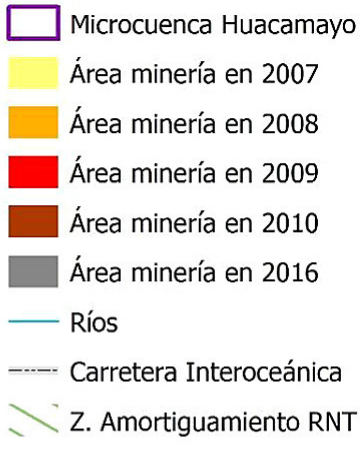

Región Madre de Dios

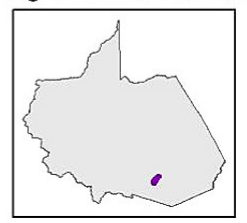

Fuentes: Imágenes ASTER del 07/04/2006, 18/08/2007 y 09/02/2008; imágenes LANDSAT del 28/08/2009 y 07/08/2010; WorldView 2 de 31/03/2016; IGN. Elaboración propia.

que han depositado el oro lavado desde la cordillera. Esta microcuenca posee una superficie de 6678 ha y una forma alargada. La microcuenca presenta dos tipos de bosques, que antes de la minería abarcaban el 93\% de la microcuenca: el pantano arbóreo y el bosque de terrazas altas (Gobierno Regional de Madre de Dios e Instituto de Investigaciones de la Amazonía Peruana, Goremad-IIAP, 2008). El primero se distribuye en las terrazas de mal drenaje y cerca del río Inambari. Tiene una baja diversidad de especies vegetales, entre las que domina el renaco (Ficus trigona y Coussapoa trinervia), mientras que el bosque de terrazas altas presenta árboles de gran altura y posee una diversidad florística media en comparación con otros bosques de la llanura amazónica (Goremad-IIAP, 2008).

La extracción aurífera empezó a desarrollarse en la parte baja desde 2007 y se fue expandiendo hacia las nacientes, sector que pertenece a la zona de amortiguamiento de la Reserva Nacional Tambopata (véase figura 1). El acelerado proceso de expansión minera se vio favorecido por el aumento del precio del oro (Swenson et al., 2011), la tecnificación del proceso extractivo (Mosquera et al., 2009) y la buena accesibilidad a la microcuenca.

El primer asentamiento identificado en el área de estudio es la comunidad Nueva Arequipa, dedicada a la agricultura cerca de la carretera desde hace cuatro décadas. 
Desde 2007, la minería constituye su fuente de ingresos, directa e indirectamente, para cientos de personas que se sitúan en campamentos dispersos y asentamientos de comercio y servicios de carácter temporal, puesto que la permanencia de población depende de la abundancia de oro. Los principales de estos asentamientos son Km. 102, Km. 103, Nueva Esperanza, Lamal Chico, Aguajal, Asociación de Comerciantes de Nueva Arequipa, y Lamal 1, 2 y 3. La población es predominantemente masculina, con una elevada presencia de población joven entre los 20 y 29 ańos, y tiene pocos niños y niñas (Instituto Nacional de Estadística e Informática, 2007).

\section{LoS IMPACTOS AMbIENTALES DE LA MiNERÍA AURífERA ALUVIAL}

Para comprender los impactos ambientales de esta actividad, se describe el proceso minero predominante en la zona de estudio en dos fases: explotación y beneficio. Asimismo, se describen los impactos directos al medio biofísico en cada fase, con apoyo de diagramas de flujo para identificar las relaciones entre impactos directos e indirectos en el ambiente. La identificación de impactos se basa en un análisis sistematizado de fuentes bibliográficas, observaciones en campo y entrevistas a especialistas. Como parte de ello, se realizó la contrastación de listas de verificación de impactos de la actividad minera (García, 1998; Sánchez, 2000; United Nations Economic Commission for Europe, 1995) y estudios de la minería aluvial aurífera en la Amazonía peruana o la región Madre de Dios (Dourojeanni, Barandiarán y Dourojeanni, 2009; Instituto de Investigaciones de la Amazonía Peruana y Ministerio del Ambiente, IIAP-Minam, 2011; Medina, 2007; Medina, Arévalo y Quea, 2007; Mosquera et al., 2009).

El proceso minero inicia con la preparación del terreno y la extracción de material, lo cual implica la tala de árboles, y la remoción y quema de toda la vegetación a cargo de los «macheteros» (véase figura 2). Luego, se extrae el material aluvial con diferentes métodos, el más común de los cuales en la zona es el de «chupadera». Este método requiere de grupos de alrededor de cuatro hombres por máquina que trabajan en turnos de doce horas. Ellos se encargan de introducir agua a presión para mezclarla con los sedimentos arcillosos que alcanzan varios metros de profundidad y la mezcla es sustraída con bombas para transportarla. Además de este, se emplean los métodos de explotación "caranchera" y «balsa gringo». La caranchera succiona material debajo del agua con el apoyo de un buzo que mueve la manguera. La balsa gringo es una unidad móvil que se desplaza sobre canoas y emplea un armazón de metal para el anclaje y para movilizar la manguera de succión (Mosquera et al., 2009). Esta balsa es empleada sobre el cauce de la quebrada y también sobre amplias pozas creadas por explotaciones previas con chupadera.

Después de succionar el material por alguno de los métodos descritos, este se vierte por unas canaletas donde, por su mayor peso, se acumula el oro en alfombras especiales (véase figura 3). Posteriormente, el agua es devuelta junto con los sedimentos finos o es vertida en el suelo, lo cual produce zonas fangosas de mal drenaje. 
Figura 2. Deforestación por la actividad minera en Huacamayo

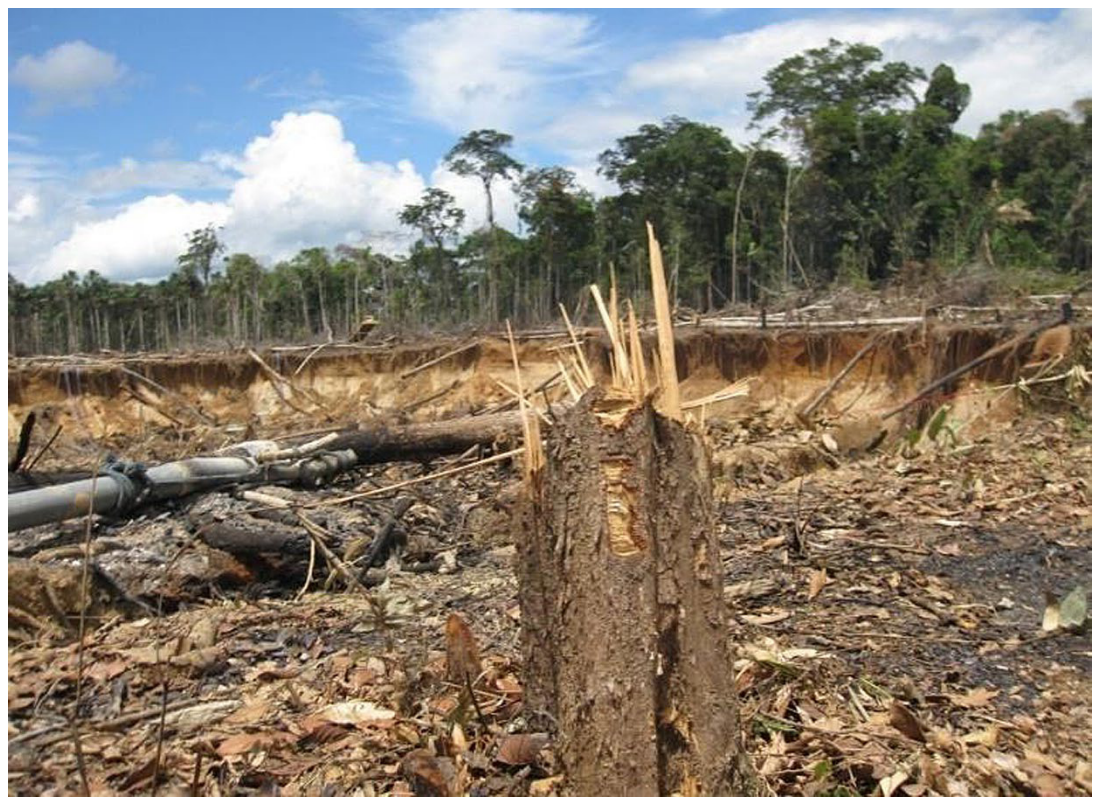

Fotografía: P. Moschella, 2009.

Figura 3. Canaletas empleadas para la concentración del material

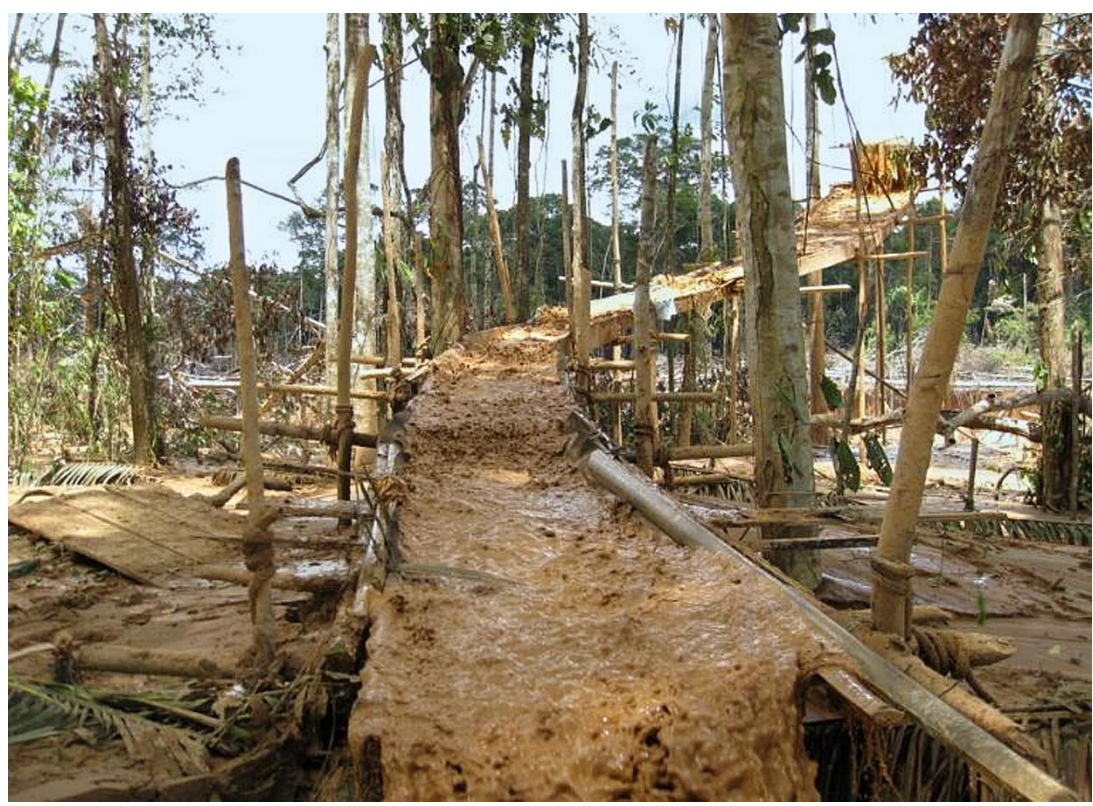

Fotografía: Y. Campos, 2009. 
En la fase de explotación, se han identificado los siguientes impactos directos: deforestación, remoción del suelo, alteración de la morfología y cauces, alteración del caudal superficial y subterráneo, contaminación por hidrocarburos, y emisión de ruido. Estos generan, a su vez, diversos impactos indirectos en el medio físico, biológico y social (véase figura 4 ).

La fase de beneficio del mineral se realiza en la misma zona donde se extrae. Consiste en separar el oro del material fino mediante el uso de mercurio. La práctica común es emplear un cilindro donde se lavan las alfombras de las canaletas que tienen altas concentraciones de oro y se añade el mercurio para permitir el proceso de amalgamación del oro con el mercurio. Finalmente, se procede a quemar la amalgama para la recuperación del oro.

A pesar de ser un elemento altamente tóxico, el mercurio tiene un uso muy extendido por ser un método simple, eficaz y de bajo costo (Medina, 2007; Neisser, 1995). Además, en la mayoría de casos, este elemento es utilizado de manera incorrecta ya que se emplearía una cantidad mayor de la necesaria para la amalgamación. Por otro lado, durante la preparación de la amalgama, los trabajadores no emplean elementos para protegerse del contacto del mercurio con la piel o evitar su inhalación. En el refogado o quema de la amalgama, muchos mineros no emplean la retorta, un recipiente que permite destilar y recuperar el mercurio para evitar la emisión de mercurio al aire. El almacenamiento tampoco es adecuado por no contar con recipientes herméticos (Medina, 2001; Mosquera et al., 2009).

Como resultado de malas prácticas en el uso del mercurio, durante la etapa de beneficio este metal es emitido al ambiente de las siguientes maneras: por evaporación durante su uso, por vertidos al suelo y agua después del lavado de alfombras, por derrames al suelo y agua de manera accidental, y por evaporación durante la quema de la amalgama. Como consecuencia, el mercurio afecta a la salud humana, y a la flora y fauna a nivel regional (véase figura 4).

Por otro lado, es importante señalar que los principales impactos sociales se relacionan con el aumento de la prostitución, la delincuencia y la corrupción en el entorno de las zonas mineras. Pero estos problemas no son inherentes al proceso minero. La alta informalidad de la economía peruana es un problema estructural y, en el caso de la minería de pequeña escala, se relaciona en gran medida con la débil presencia del Estado (Romero, Pachas, Zambrano y Guarniz, 2005). Eliminar graves problemas en las zonas mineras como los relacionados con las denuncias por explotación infantil y trata de personas requiere de un control eficiente de la policía y las autoridades locales.

En la valoración que señala Medina et al., la deforestación es el principal impacto del método de explotación empleado en la zona (2007); mientras que, a nivel regional, el Ministerio del Ambiente identifica la contaminación por mercurio como el principal impacto de esta actividad debido a su alta toxicidad (IIAP-Minam, 2011). Por estas razones, a continuación, se analizarán con mayor detalle ambos impactos. 
Figura 4. Principales impactos ambientales de la minería y sus interacciones

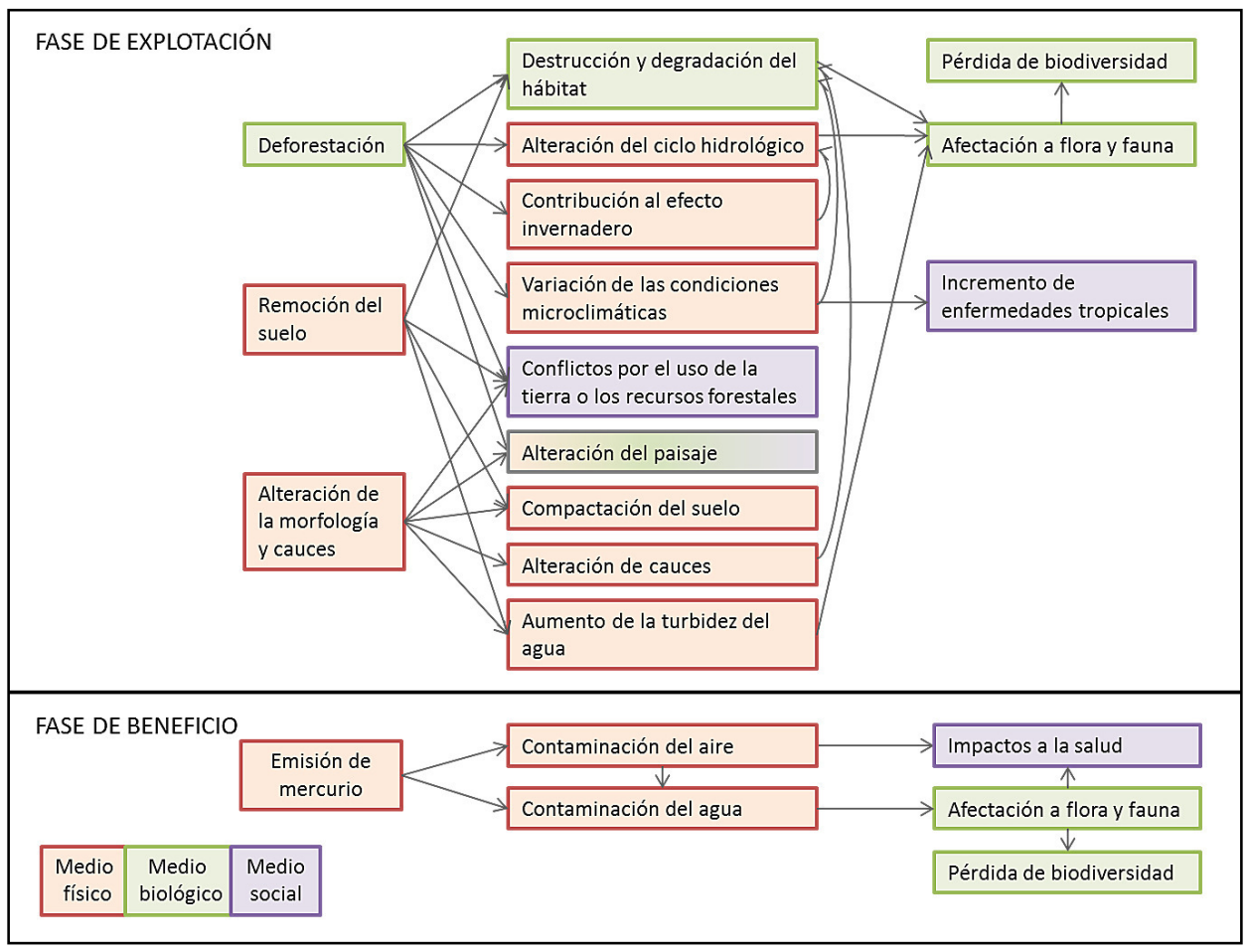

\section{a. Deforestación y estrategias de mitigación}

La tala y quema de la vegetación para la explotación minera trae como consecuencia una serie de procesos de degradación del medio físico y biológico asociados entre sí, además de efectos sobre el medio social. Dourojeanni indica que las predecibles consecuencias de la deforestación en la Amazonía peruana «se imbrican y encadenan unas con otras, en una interminable sucesión de consecuencias trágicas» (1990, p. 86). A nivel biológico, se destruye el hábitat de diversas especies de fauna. Algunos animales pequeños, sobre todo invertebrados, son exterminados, mientras que los animales con capacidad de movimiento se trasladan a zonas que seguramente ya están ocupadas y que podrían carecer de mayor capacidad (Dourojeanni, 1990). Además, la deforestación en Huacamayo genera una amplia barrera para la movilidad de individuos y el flujo del material genético.

En el medio físico, los impactos de la deforestación se pueden identificar en distintas escalas. A nivel global, la deforestación en Huacamayo contribuye a incrementar el efecto invernadero por la emisión de dióxido de carbono al aire durante la quema de la vegetación y por la reducción de bosques con capacidad de absorción de carbono. 
A nivel regional, altera directamente el ciclo del agua, puesto que se reduce la evapotranspiración y la capacidad de retención del agua. A nivel local, altera el comportamiento de la escorrentía y el caudal de la quebrada Huacamayo; y altera también las condiciones microclimáticas, con lo cual se genera mayor temperatura y menor humedad en la zona deforestada. Asimismo, en todo el borde del bosque colindante, se produce una gradiente de variación microclimática cuya influencia podría alcanzar entre $20 \mathrm{~m}$ y $70 \mathrm{~m}$, y sus consecuencias en la estructura de la vegetación, hasta $150 \mathrm{~m}$ al interior del bosque (Laverty y Gibbs, 2010; Murcia, 1995).

Por otro lado, el aumento de temperatura crea condiciones favorables para los vectores de enfermedades tropicales (Dourojeanni, 1990). La Dirección Regional de Salud (Diresa) señala mayor incidencia de malaria en las zonas mineras debido a las condiciones climáticas y al desconocimiento de medidas de prevención (Diresa, 2010). Además, la eliminación de la vegetación favorece los procesos de erosión y compactación del suelo por acción de las lluvias (Scott, 1981).

En cuanto a los impactos sociales de la deforestación en Huacamayo, puede destacarse la ocurrencia de conflictos por el uso de los recursos forestales. Asimismo, la deforestación ha generado una gran alteración del paisaje que se puede presenciar desde la carretera, con lo cual se reduce el potencial paisajístico y turístico de la zona.

La dimensión de la deforestación en la microcuenca Huacamayo se analizó a partir de imágenes satelitales. En el año 2006, existían huellas muy pequeñas de intervención humana solo en la parte sur, debido a la actividad agropecuaria a los lados de la carretera. Recién en 2007, se inició la extracción minera cerca de la desembocadura de la quebrada en el río Inambari, y, en 2009, se conformó una zona minera bastante amplia y continua con un ancho de más de $1 \mathrm{~km}$. Posteriormente, continuó la expansión hacia el sur e ingresó a la Zona de Amortiguamiento de la Reserva Nacional Tambopata, pero a una velocidad menor por el agotamiento de las reservas de oro, y la actividad se trasladó a las microcuencas vecinas.

La principal medida de mitigación de estos impactos es la reforestación después de la extracción minera. El bosque tiene la capacidad de restauración natural, como parte de un proceso de sucesión de comunidades vegetales que contribuyen a formar el suelo necesario para la vegetación y al incremento de la diversidad de especies de flora y fauna.

La perturbación de la minería en Huacamayo es de gran consideración por su tamańo y duración; sin embargo, aun en casos graves, puede suceder una recuperación, aunque lenta (Uhl, 1989). Por ejemplo, en el sector Fortuna, $28 \mathrm{~km}$ al noreste de la microcuenca Huacamayo, se puede apreciar la regeneración natural del ecosistema sobre pilas abandonadas con el crecimiento de especies pioneras de varios metros de altura; incluso las fosas abandonadas por la minería pueden albergar peces que llegan durante la crecida de los ríos (véase figura 5). La revegetación natural de antiguas zonas mineras también ha sido registrada en el proyecto piloto de rehabilitación del 
área minera Huepetuhe-Caychive (Programa de las Naciones Unidas para el Medio Ambiente, 2004). Cabe indicar que la composición de flora y fauna en estas áreas restablecidas corresponde a etapas juveniles en la sucesión, ya que el bosque maduro es resultado de un desarrollo estimado en doscientos años. Además, la composición de la sucesión tardía podría ser diferente de la original.

Las prácticas para reducir los impactos ambientales de la explotación minera deben restablecer la morfología, el suelo y la vegetación. En primer lugar, deberían reducirse las pilas de grava y rellenar las fosas. En cuanto al suelo, al iniciar la explotación, este debe ser retirado y almacenado para ser devuelto al finalizar. Finalmente, se debe reforestar con especies nativas, sobre todo con árboles que atraen animales que lleven semillas para contribuir a la diversificación de especies (Uhl, 1989). Si se han perdido las capas superficiales de suelo, Medina recomienda utilizar «especies arbóreas pioneras con capacidad de formar simbiosis con bacterias diazotróficas», de manera que puedan generar el nitrógeno necesario y obtengan mayor eficiencia en el uso del agua y nutrientes (Medina, 2007).

Para cumplir con la ejecución de estas prácticas, una alternativa es la certificación del oro verde, que paga una prima como un incentivo «que valora la conservación y restauración de servicios ambientales» (Ayala, 2003). En el sector Huacamayo, ya existen algunas labores de reforestación, principalmente con especies de crecimiento rápido o especies frutales para consumo humano.

Figura 5. Zona minera abandonada de veinte años de antigüedad en sector Fortuna

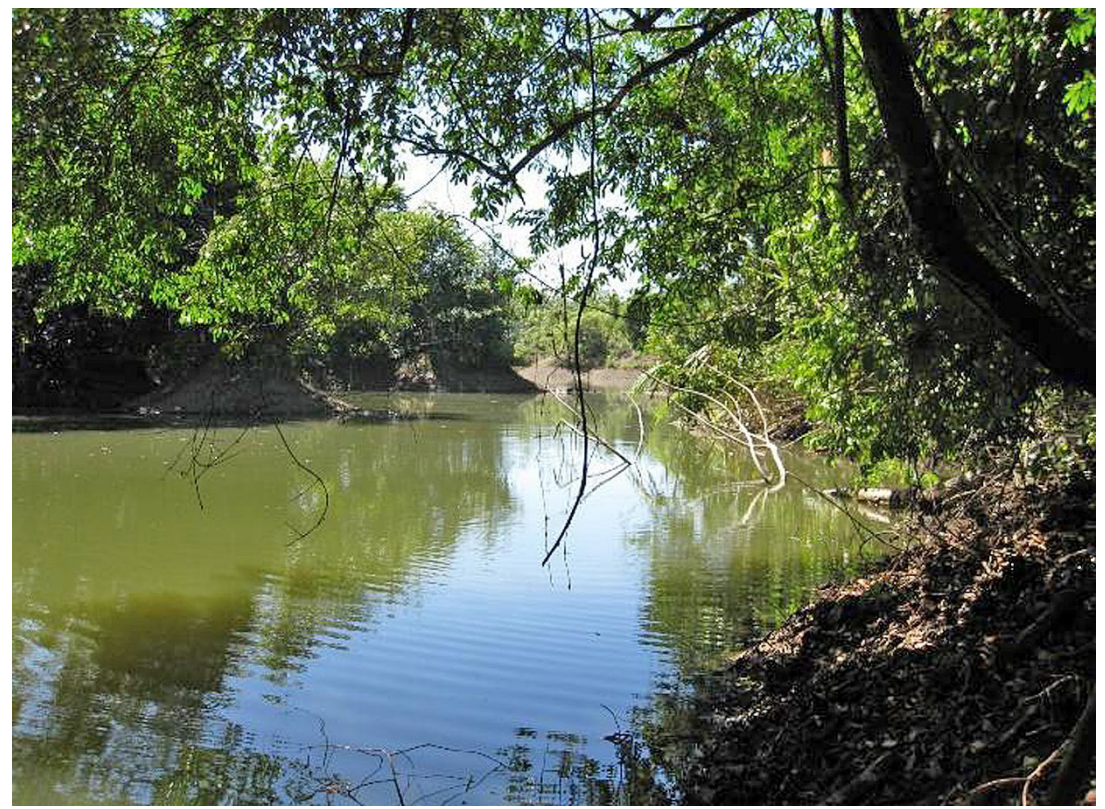

Fotografía: P. Moschella, 2010. 
Además, se pueden integrar nuevas tecnologías de percepción remota por imágenes satelitales o drones para mejorar el control de las áreas de extracción minera, caracterizadas por las dificultades de acceso.

\section{b. Contaminación por mercurio y alternativas de uso controlado}

Una vez en el ambiente, el mercurio transforma su composición química y se traslada de manera cíclica entre componentes físicos y biológicos del medio. El mercurio metálico $\left(\mathrm{Hg}^{0}\right)$ que la minería derrama sobre el suelo se puede evaporar con facilidad o ser transportado por las lluvias hacia los cuerpos de agua. Ya sea desde el agua, los sedimentos o el suelo, el mercurio metálico se puede volatilizar o sedimentar. El mercurio que llega a la atmósfera puede mantenerse un año allí y ser transportado a grandes distancias (Organización Mundial de la Salud, OMS, 2005; Spiro y Stigliani, 2004). En la atmósfera, se puede convertir en ion mercúrico $\left(\mathrm{Hg}^{2+}\right)$, que se deposita con la lluvia o por gravedad sobre el suelo y puede llegar de manera directa o indirecta al agua y a los sedimentos. El ion mercúrico $\left(\mathrm{Hg}^{2+}\right)$ presente en los sedimentos acuáticos se transforma por acción bacteriana en metilmercurio o dimetilmercurio (Spiro y Stigliani, 2004; Tello, 2002). Debido a que las aguas de la zona de estudio tienen un $\mathrm{pH}$ ácido, la mayor parte del mercurio es transformado en metilmercurio $\left(\mathrm{CH}_{3} \mathrm{Hg}^{+}\right)$, el cual es la forma más tóxica del mercurio (OMS, 2005; Tello, 2002; Usepa, 2010). De esta forma, el metilmercurio que se encuentra en el agua es absorbido por peces e invertebrados, y se acumula como metilmercurio u otros compuestos orgánicos en distintos tejidos. Después, va a transportarse a otros organismos por la cadena trófica, donde se biomagnifica, lo que significa que, en los niveles tróficos mayores, la concentración de mercurio es mayor.

Se estima que del mercurio empleado para la formación de la amalgama, el 50\% se vierte al suelo o agua (Hacon y Azevedo, 2006), del cual el 55\% volatiliza y el resto permanece en ríos, lagos y sus sedimentos (Neisser, 1995). Del otro $50 \%$ que se encuentra en la amalgama, el $45 \%$ será refogado en la zona de extracción o campamentos, y el resto permanecerá con el oro refogado y es muy probable que sea emitido al aire durante la refinación en las tiendas comercializadoras por carecer de sistemas eficientes de control (Usepa, 2008). Considerando el volumen estimado de material removido en la microcuenca, la ley de oro promedio en la zona (Goremad, 2009), la proporción de mercurio empleado por medida de oro (Hacon y Azevedo, 2006; Mosquera et al., 2009) y que el $70 \%$ del mercurio empleado finalmente se volatiliza al aire, se estima que el volumen de mercurio metálico emitido por la minería al aire en Huacamayo hasta agosto de 2010 es de 114 toneladas.

Las concentraciones mayores se dan durante el refogado en las zonas inmediatas cuando no se usa la retorta. Se presume que las altas concentraciones de mercurio en el 
aire pueden disminuir rápidamente por debajo del nivel recomendado por la OMS en unos $200 \mathrm{~m}$ de la zona de quema de amalgama (Usepa, 2008). Sin embargo, estudios realizados en Brasil detectaron niveles anormales en un radio de $200 \mathrm{~km}$ de la zona donde se realiza el refogado (Malm, 1990, como se citó en Neisser, 1995).

La contaminación de mercurio en todas sus formas en el agua y aire no puede ser estudiada solamente dentro de la microcuenca, ya que el mercurio es transportado por la lluvia y los ríos. Asimismo, la fauna acuática contaminada se traslada constantemente. Por tanto, este tipo de contaminación debe ser analizada a escala regional, donde también intervienen las emisiones de otras zonas mineras de Madre de Dios.

Según el monitoreo de recursos hídricos a cargo de la Dirección Regional de Salud (2010) en las estaciones cercanas entre 2008 y 2010, los ańos de mayor explotación minera en Huacamayo, la concentración de mercurio en el agua no sobrepasó el estándar de calidad ambiental (ECA). Sin embargo, el estudio de Diringer et al. (2015) confirma que las concentraciones de mercurio en sedimentos en el río Madre de Dios van aumentando aguas abajo de la zona minera de Huacamayo, y en el río Inambari se identifica la mayor concentración de metilmercurio en sedimentos.

Debido a la bioacumulación, hay estudios que demuestran altas concentraciones de mercurio en los peces carnívoros de la región. Por ejemplo, en tres de las especies más consumidas en Puerto Maldonado, Mota Punteada, Zúngaro y Chambira, se hallaron concentraciones por encima del límite máximo de la OMS (Fernández y González, 2019, p. 28). De modo similar, en el río Madre de Dios, se encontró que el 30\% de los peces carnívoros tienen concentraciones de mercurio que exceden los límites permitidos para el consumo humano (Diringer et al., 2015).

Los síntomas de intoxicación por inhalación de mercurio metálico son temblores, inestabilidad emocional, insomnio, debilidad muscular, dolor de cabeza, trastornos de la visión y la audición, parálisis, entre otros. Una alta y prolongada exposición puede afectar los rińones, la respiración y el sistema digestivo, e incluso causar la muerte (OMS, 2005; Spiro y Stigliani, 2004; United States Environmental Protection Agency, Usepa, 2010).

En cambio, los síntomas de la intoxicación por metilmercurio son alteraciones neurológicas; alteración de la visión, el tacto, el habla y la audición; falta de coordinación; y debilidad muscular (Usepa, 2010). Debido a que los síntomas, en general, se presentan después de varios años de exposición, es difícil evidenciar los problemas de salud que ocasiona la exposición al mercurio en la región (Fernández y González, 2019). La principal vía de intoxicación por metilmercurio es el consumo de pescado contaminado, donde el metilmercurio se bioacumula (Spiro y Stigliani, 2004; Tello, 2002). El estudio de Tschirhart (2011), realizado en las orillas del río Beni, en el cual desemboca el río Madre de Dios, evidencia que la población más vulnerable a la contaminación por mercurio es la que tiene una dieta conformada en mayor medida 
por pescado, por lo que se encuentran en alto riesgo las poblaciones indígenas de la cuenca. En la salud humana, Ashe (2012) identifica que un $11 \%$ de residentes en zonas mineras tienen concentraciones de mercurio dañinas para la salud.

Ante los problemas de contaminación por mercurio en la minería, existen tecnologías de beneficio sin mercurio por gravimetría o flotación, como las que ya se han desarrollado en el país (La República, 2012). También se podría evitar el uso inadecuado del mercurio controlando su libre comercialización para evitar su uso en áreas mineras dispersas, y promoviendo la creación de centros de beneficio donde se asegure un mayor control del uso del mercurio y se instalen retortas comunales para el refogado y recolectores de mercurio para un requemado más eficiente.

Como se mencionó, un incentivo para mejorar las prácticas puede ser la certificación del oro, que implica el pago de una prima por cumplir con mejores estándares ambientales (Ayala, 2003).

\section{LA PERCEPCIÓN AMBIENTAL LOCAL}

Se analizó la percepción de la población respecto de los impactos ambientales de la minería y su disposición a adoptar medidas de reducción de impactos. El análisis se basó en un sondeo aleatorio a sesenta habitantes de la microcuenca, y en catorce entrevistas detalladas a empresarios y obreros mineros, y al presidente de una comunidad agrícola.

De manera general, las menciones espontáneas de los impactos al ambiente físico y biológico fueron muy reducidas. Cuando se solicitó a los entrevistados una explicación detallada del proceso de explotación, ninguno manifestó por iniciativa propia los impactos ambientales. Asimismo, al preguntar de manera abierta sobre lo menos agradable de la minería, la mayoría se centró en señalar lo duro y riesgoso del trabajo, así como los principales problemas sociales. Muy pocas personas hicieron referencias generales a la contaminación y depredación del bosque.

A continuación, se presentan los resultados de la percepción de los impactos de la minería en las fases de explotación y de beneficio a partir de la indagación con preguntas más directas:

\section{a. Percepción de la deforestación y de las medidas de reforestación}

El impacto más claramente percibido como consecuencia de la deforestación es la variación microclimática de la temperatura: el $57 \%$ de los encuestados señaló esta variación como el impacto más evidente. Asimismo, se manifestó un reconocimiento relativamente certero de la magnitud de la deforestación por la actividad minera en Huacamayo, cuyo promedio de deforestación es de 36\% del área de la microcuenca, frente al cálculo de $31 \%$ a partir de imágenes satelitales hasta agosto de 2010. 
Son pocos los que consideran el impacto negativo de la deforestación en lo que respecta a la degradación o fragmentación del hábitat. Por lo general, indican que los animales no se ven afectados ya que pueden migrar a otros sectores. En cambio, el 5\% de encuestados identificó mejor la afectación sobre recursos como la caza de animales o la extracción/producción de madera. Sin embargo, muy pocos consideran que el bosque próximo también se vea alterado.

Respecto de la gravedad de la deforestación, como parte de la investigación se consultó si el bosque vuelve a crecer después de la minería. El 22\% opina que no vuelve a crecer, con comentarios como «solo mala yerba crece, pero, si le echas un abono, puede ser». Mientras que el $62 \%$ confirma el desarrollo de una revegetación natural, que varios han visto en zonas mineras abandonadas; entre estos, el $32 \%$ indica que vuelve a crecer igual que antes y el $30 \%$, que crece pero diferente. Una opinión de la primera posición fue: «He visto $[. .$.$] que donde se ha trabajado la minería crece [...] cada año el río se$ desborda y se limpia y se llena de vegetación [...] de acá a veinte años, cien años [...] parece mentira pero [se] recupera». Pero otros opinan que se regenera un bosque de composición distinta: «El monte vuelve a crecer pero solo árboles corrientes, no cedro ni caoba». Además, se consultó por el tiempo que demora el bosque en regenerarse. La respuesta promedio es doce años, con respuestas que van de uno a cincuenta años. Es decir, algunos consideran que se regenera desde que aparecen las primeras plantas, mientras que otros piensan que la regeneración del bosque implica el desarrollo de ciertas especies de gran tamaño. Esta variedad en la percepción nos aproxima a las diferencias de valoración que se le da al bosque como una simple cobertura vegetal o como el espacio de desarrollo de grandes árboles específicos.

En cuanto a la valoración del problema de la deforestación por la minería, el 37\% lo considera un problema grave y el $17 \%$ respondió que no es un problema. Las reacciones son diversas. Algunos se desligan de la responsabilidad y lo adjudican a «los otros». Otros encuestados mostraban una posición confusa al reconocer los impactos pero minimizándolos. Mientras tanto, otro grupo reconoce las consecuencias, pero las justifica por ser su medio de vida, con comentarios como: «Pero yo vivo de la minería», «Se sabe que se hace un daño al ambiente, pero ¿dónde más se va a trabajar? La gente tiene que comer».

Al desagregar la valoración de la deforestación por sexo de los encuestados, se obtiene que, en mayor proporción, las mujeres la consideran un problema grave. Por otro lado, según departamento de origen de los encuestados, el 58\% de inmigrantes la considera un problema grave frente al $33 \%$ de oriundos de Madre de Dios que resalta su gravedad.

Sobre la adopción de medidas de mitigación, una mayoría (42\%) no opina ante la consulta sobre si estarían de acuerdo con la reducción del área que se deforesta por la minería, mientras que el resto se divide en posiciones opuestas. Se comentó, por ejemplo, que «no se puede reducir el corte de monte». La medida con la que sí está 
de acuerdo la mayoría (65\%) es que los mineros reforesten después de la extracción, frente a un $5 \%$ en desacuerdo. Se apreció buena disposición de la mayoría a pesar de implicar una inversión de tiempo y dinero. Se comentó, por ejemplo, que «mientras se reforeste, habrá algo de vida aunque sea». También se apreció la prioridad de reforestar para la agricultura antes que por la restauración ambiental.

\section{b. Percepción de la contaminación por mercurio y de las alternativas de mitigación}

El impacto de las emisiones de mercurio en la salud fue identificado por la mayoría. El 42\% afirmó que respirar una vez el humo del mercurio puede causar enfermedades y la respuesta aumentó a $62 \%$ en el caso de respirar el humo durante varios años. Sin embargo, en ambas preguntas, un alto porcentaje (33\%) no respondió debido al desconocimiento. Hay afirmaciones opuestas: quienes afirman conocer personas con problemas de salud por la exposición al mercurio, y quienes argumentan que llevan años en minería y nunca se han enfermado. Pero algunos expresaron duda o preocupación: "Tengo entendido que te puede dar enfermedades, pero, en todo el tiempo que tengo, yo jamás he visto nada», "No se siente que hace daño, pero de repente, en más tiempo, puede ser». También se minimiza el problema por ser a largo plazo: «De hecho que me va a hacer daño pero cuando esté viejo». De modo similar, el 50\% afirmó que el humo de la quema de la amalgama puede afectar a los asentamientos cercanos.

Por otro lado, el 53\% no sabía si el mercurio se elimina o desaparece en caso de que ingrese al organismo, lo que muestra la gran desinformación sobre este asunto. Algunos mencionaron que se elimina en días u horas, y hacían referencia al supuesto caso de una nińa que bebió una botella de mercurio sin ser afectada. En cambio, el movimiento del mercurio en el ambiente sí fue percibido con mayor facilidad; de hecho, el 58\% afirmó que el humo del mercurio después cae al agua. Pocas personas se mostraron convencidas de que no implica un real impacto ambiental; en estos casos, sus afirmaciones era como las siguientes: "El mercurio no se junta con el agua», "Cae en aguas estancadas por lo que no afecta mucho», «El mercurio tiene peso; el agua no lo lleva».

Además, el 58\% confirmó que los peces se encuentran contaminados por mercurio, sobre todo por información difundida en medios de comunicación masiva. Algunas personas señalaron que «el mercurio los mata y ya no hay pescado» e, incluso, que «en un pescado encuentras en su barriga el azogue». En cambio, otros se mostraron desconfiados de esta información: «Dicen que el pescado tiene azogue, pero yo no le encuentro nada [...] le reviso todito y no le encuentro», «Dicen que hace daño, pero ¿dónde están las pruebas? Que nos presenten una prueba técnica científica».

Asimismo, el 67\% considera que el uso del mercurio por la minería es un problema. Entre ellos, el 37\% lo considera un problema grave. Otras personas no están convencidas de la toxicidad del mercurio o intentan minimizar el impacto frente a la necesidad de 
utilizarlo en su trabajo. Un entrevistado sintetizó el problema: «Todos saben que el mercurio afecta. Es más la necesidad: es la enfermedad o el dinero. El dinero mueve el mundo». Según departamento de origen, hay una amplia diferencia entre quienes opinan que el uso del mercurio es un problema grave: el 35\% de las personas nacidas en Madre de Dios así lo considera, mientras que el porcentaje de personas inmigrantes que opinan de esta manera asciende a 57\%.

Entre quienes no lo consideran un problema, hay dos argumentos principales: el desconocimiento de casos de problemas en la salud o el ambiente, y la afirmación de que el uso de retortas no supone la emisión de mercurio al ambiente.

Por otro lado, el $50 \%$ de los encuestados opinó que sí es necesario un mayor cuidado al usar el mercurio, frente al $8 \%$ que opina que no es necesario. Respecto a la alternativa de emplear una técnica sin mercurio, el 50\% se mostró de acuerdo, el 38\% no respondió y el $12 \%$ expresó su desacuerdo. Se obtuvo todo tipo de comentarios respecto del conocimiento de otras técnicas, desde haber asistido a capacitaciones al respecto hasta que «no se puede» $\mathrm{O}$ «no existen» técnicas sin mercurio.

Finalmente, segmentando solo a los mineros encuestados (veintitrés personas), el $39 \%$ señaló que utiliza la retorta siempre; el $17 \%$, que la utiliza a veces; el $9 \%$, que no la utiliza; y el 35\% no respondió. Algunos manifestaron su poca preocupación en la manipulación del mercurio y la desventaja del uso de la retorta, que requiere más dinero y tiempo, aproximadamente dos horas, frente al refogado directo que supone treinta minutos. Asimismo, la gran mayoría de los mineros explicó con bastante naturalidad que tocan directamente el mercurio con sus manos y no usan guantes, ya sea por costumbre o incomodidad, o por considerarlo innecesario. Algunos de los mineros se mostraron contrarios al uso de técnicas sin mercurio debido al tiempo que requieren o al costo, o por considerar innecesario evitar el uso del mercurio. Destacaron las siguientes afirmaciones: «Tantos que han venido a hablar de eso, pero no es igual [...] es pérdida de tiempo. ¿Quién va a estar ahí todo el día?», "Ha habido capacitaciones $[\ldots]$ pero, no sé, no creo que es necesario [...] usas la retorta y así ya no sale el vapor».

\section{c. Factores que intervienen en la percepción ambiental}

Los impactos ambientales identificados con mayor facilidad fueron la alteración de la morfología, del cauce y del paisaje. Estos cambios se pueden observar fácilmente desde la carretera, lo que facilita una exposición constante para su fijación en la imagen mental de la población. Asimismo, se reconoció con relativa certeza la magnitud de la deforestación por la minería en Huacamayo, cuya percepción proviene de la observación directa y la comunicación interpersonal.

Por otro lado, a pesar de no requerir de conocimientos complejos para deducir los impactos de afectación de la flora y fauna, ni la reducción del hábitat terrestre y 
acuático, estos no fueron percibidos por la población en una dimensión proporcional a lo confirmado a partir de las fuentes científicas. Probablemente, se debe a una reducida valoración de la flora y fauna silvestres, así como del ecosistema del bosque tropical en su conjunto. Esta baja percepción contrasta con la aceptación de la mayoría de encuestados de la afectación a la caza y a la actividad forestal. A partir de ello, se puede inferir la predominancia de un razonamiento extractivista y antropocéntrico, ya que la población percibe con mayor facilidad el impacto a los recursos naturales de explotación directa que el impacto a los recursos potenciales o a componentes ambientales que no ofrecen un beneficio directo.

Igualmente, se ha observado que la mayoría no comprende cabalmente los impactos indirectos a partir de la explotación, por lo que su valoración es relativamente baja. En general, se ha manifestado una apreciación muy superficial del bosque. Se le identifica como un elemento positivo de la naturaleza, pero no se valoran de manera significativa todos los servicios que provee.

La débil valoración también se puede relacionar con la práctica generalizada de la tala para el desarrollo de actividades agropecuarias o para el asentamiento de la población. Este punto también puede ser discutido dentro del marco jurídico de concesión de derechos, según el cual se asumen como aspectos separados los derechos mineros y los agrarios, lo cual, según Mosqueira, «incentiva la depredación [...] ya que el minero que extrae el oro [...] no tendrá interés en dejar la tierra en buen estado» (1992, p. 54).

En cambio, el impacto de la variación microclimática se puede percibir directamente por los sentidos, además de ser una característica ambiental que ocasiona gran incomodidad. Por estas razones, este tipo de impacto es fácilmente retenido en la imagen mental, sin necesidad de reflexionar sobre los procesos que lo explican. Otro impacto cuya percepción se basa en razones similares es el aumento de enfermedades tropicales, identificado por varios entrevistados que hacían referencia a su experiencia, sin recurrir a interpretaciones sobre la creación de condiciones favorables para los vectores de enfermedades.

Entre los impactos que no fueron identificados por los entrevistados, se encuentra el aumento de la turbidez del agua, posiblemente debido a que los ríos son naturalmente turbios en la zona y porque percibir el incremento de la turbidez requeriría de instrumentos. De igual forma, la alteración del ciclo hidrológico y la pérdida de biodiversidad no fueron identificados explícitamente por requerir de un mayor conocimiento y comprensión de los procesos ambientales.

En cuanto a los impactos de la fase de beneficio, se observa que la mayoría identifica los principales impactos a la salud y al ambiente. Sin embargo, el alto porcentaje de personas que no dan una respuesta a las preguntas evidencia un nivel limitado de comprensión de los impactos. Además, gran parte de los argumentos se basa en suposiciones personales. Se aprecia que la construcción de la imagen mental de los impactos 
de la etapa de beneficio es más difusa. Según lo declarado, las fuentes de información son la experiencia, las noticias, la comunicación interpersonal y las capacitaciones a mineros. Existen, por tanto, fuentes diversas pero con una limitada disponibilidad y calidad de la información.

Se podría decir que, en este caso, predomina el conocimiento ambiental deductivo a partir de la experiencia: fue predominante la elaboración de suposiciones sobre el comportamiento del mercurio en el ambiente a partir del conocimiento básico de las características físicas del mercurio metálico, sin considerar que este metal puede estar en otras formas o compuestos. En tal sentido, Gold (1980) resalta que la percepción es dominantemente visual, que tiene un alcance mayor que otros sentidos; por ello, ver es considerado cercano al creer.

A partir de la comparación entre los impactos ambientales identificados de manera objetiva y la percepción local de estos, se puede confirmar que el nivel de percepción de los impactos depende en gran parte de la posibilidad de percibirlos directamente. Otros factores relacionados son la capacidad de comprensión de las causas y procesos que intervienen en el impacto, la posibilidad de medir sus características, la disponibilidad de información, y las condiciones ambientales a las que las personas están acostumbradas.

En el caso de los impactos de la fase de explotación, se ha encontrado un buen nivel de percepción de los impactos, facilitada por la posibilidad de observar directamente algunas de sus características y la capacidad de comprender algunos efectos directos. Sin embargo, la valoración de estos impactos es relativamente baja debido a la débil apreciación del bosque y los servicios que ofrece. En el caso de los impactos de la fase de beneficio, la población posee una percepción confusa e imprecisa, basada en una deficiente disponibilidad de información debido a la ausencia de posibilidades de observación directa de los efectos y a la carencia de una buena comprensión del problema.

Otros factores que influyen en el nivel de percepción de los impactos y que merecen ser analizados en posteriores investigaciones son el género y el lugar de origen. A partir de los resultados de la percepción y la valoración de los impactos de la deforestación y del uso del mercurio, es importante resaltar un mayor reconocimiento de estos problemas entre las mujeres, posiblemente por una mayor sensibilidad respecto de los aspectos ambientales. De igual forma, entre los resultados desagregados por origen o procedencia de los encuestados, impresiona que la población inmigrante considere estos impactos como problemas graves en mayor medida que la población nacida en Madre de Dios. Una experiencia de mayor intensidad permite establecer vínculos más fuertes con el lugar y proveer significados al espacio, por lo que se esperaría que la población de Madre de Dios muestre una mayor preocupación por el entorno y les asigne una mayor importancia a los impactos ambientales que afectan este entorno. 
Por otro lado, algunos autores señalan una tendencia a no reconocer los impactos cuando las personas se sienten identificadas con la causa del problema (Bernex, 2008; Nickerson, 2003). En cuanto a la valoración de la deforestación, los resultados presentan una ligera tendencia entre las personas que no trabajan en minería a considerar la deforestación como un problema grave, en contraste con la mayoría de los mineros, que la consideran un problema leve. Se confirma, así, una ligera tendencia a minimizar el impacto de la deforestación causada por la minería según el nivel de identificación con la causa del problema.

Respecto de la correlación entre el nivel de dependencia de la minería y la valoración del uso de mercurio por parte de esta, no hay una tendencia marcada. Un gran porcentaje de los encuestados considera que el uso de mercurio es un problema grave independientemente de la actividad a la que se dedican. Entre quienes lo consideran un problema leve, sí existe una mayor proporción en el caso de los mineros; sin embargo, esta diferencia se podría explicar por la dificultad de observación directa de los efectos negativos entre la población que acostumbra manipular este metal.

Entonces, a partir del análisis de la relación entre, por un lado, la valoración de los impactos de la deforestación y el uso del mercurio, y, por otro, el nivel de dependencia de la minería, se concluye que no es estricta la tendencia a minimizar los impactos autogenerados. Más bien, se aprecia que el reconocimiento de los impactos de la minería en Huacamayo dependerá de varios factores, y el nivel de identificación con la causa del problema no ejerce tanta influencia.

\section{Conclusiones}

La minería aurífera aluvial de pequeña escala en la Amazonía sur peruana cuenta con potencial para convertirse en una estrategia de desarrollo inclusivo en la región si se formaliza y se realiza bajo mejores condiciones ambientales. A partir del estudio de la quebrada Huacamayo, se ha identificado que los impactos directos principales son la deforestación, que destruye bosques y pantanos tropicales, y la emisión de mercurio al ambiente, que contamina el agua y fauna acuática a nivel regional y expone a la población al peligro de intoxicación por consumo de pescado contaminado.

La mitigación de los impactos ambientales de la explotación minera es posible mediante estrategias de restablecimiento de la morfología, del suelo y de la vegetación, junto con medidas de control de las áreas de extracción por percepción remota. Asimismo, la contaminación por mercurio se puede evitar empleando tecnologías de beneficio sin mercurio por gravimetría o flotación, o al menos se puede reducir controlando su uso exclusivamente en centros de beneficio que cumplan con rigurosas medidas de control. Como estrategias de apoyo, se puede contar con certificaciones ambientales que sirvan de incentivo económico para implementar mejoras. 
El análisis de la percepción local de los impactos ambientales de la extracción minera demuestra un buen nivel de identificación de los impactos directos, a la vez que una escasa comprensión de los impactos indirectos. Por un lado, este tipo de minería permite la observación directa de importantes alteraciones en la vegetación, el suelo y los cursos de agua; pero, por otro lado, se evidencian dificultades para reconocer la diversidad de interacciones en el medio natural, sobre todo en relación con la consecuente afectación en los niveles hidrológico y ecológico. Asimismo, se advierte una pobre valoración del bosque y los servicios ecosistémicos que este brinda, relacionada, posiblemente, con la predominancia de la lógica extractivista y antropocéntrica, que se refleja también en la tala generalizada para el desarrollo de actividades agropecuarias.

Particularmente, los impactos vinculados con el uso del mercurio se conocen, pero no se comprenden. Se demuestra que la población local identifica los principales impactos a la salud y al ambiente de modo impreciso debido a la carencia de información y a la imposibilidad de observación directa de la transformación química del mercurio en el ambiente.

Como vemos, el nivel de percepción de los impactos dependerá, en gran parte, de la posibilidad de percibirlos directamente, así como de la capacidad de comprensión de las causas y procesos que intervienen en ellos, la posibilidad de medir sus características, la disponibilidad de información, y las condiciones ambientales a las que las personas están acostumbradas. El nivel de identificación con la causa del problema no ejerce tanta influencia en la percepción de los impactos de la minería en Huacamayo, de modo que no es estricta la tendencia a minimizar los impactos autogenerados. Otros factores que influyen en el nivel de percepción de los impactos y merecen ser analizados con profundidad en posteriores investigaciones son el género y el lugar de origen, ya que se observa una mayor valoración de los problemas de la deforestación y uso del mercurio entre las mujeres y la población inmigrante.

En síntesis, desde la consideración de que la percepción ambiental de las personas es la base para la toma de decisiones, se concluye que la débil apreciación del bosque y los servicios que ofrece, sumada a la predominancia de la lógica extractivista, han permitido la toma de acciones que han degradado el ambiente de la microcuenca Huacamayo. Por esta razón, es necesario promover la revaloración de los servicios ecosistémicos.

Es importante destacar que la mayoría de la población sí identifica los principales impactos de la actividad minera y manifiesta su disposición a adoptar medidas para reducir los impactos ambientales mientras estas no impliquen la privación de su principal medio de sustento. Se debería aprovechar, entonces, esta disposición de la población mediante la orientación técnica, incentivos económicos o instrumentos de control. Finalmente, un segmento minoritario ignora o rechaza los impactos de la minería y manifiesta actitudes negativas respecto de un aprovechamiento más sostenible de los recursos de la región. Es necesaria, por tanto, una mayor difusión de los impactos 
de esta actividad, especialmente de las evidencias de la contaminación por mercurio y sus consecuencias sobre la salud humana y el ambiente.

La comprensión de la percepción ambiental local y de la opinión sobre las estrategias de mitigación de impactos ambientales permitirá identificar estrategias que integren adecuadamente a los actores locales para mejorar el desarrollo de esta actividad y su relación con el espacio amazónico.

\section{REFERENCIAS BIBLIOGRÁFICAS}

Argent, N. M. y Walmsley, D. J. (2009). From the inside looking out and the outside looking in: whatever happened to 'behavioural geography'? Geographical Research, 47(2), 192-203. https://doi.org/10.1111/j.1745-5871.2009.00571.x

Ashe, K. (2012). Elevated mercury concentrations in humans of Madre de Dios, Peru. PLoS ONE, 7(3). https://doi.org/10.1371/journal.pone.0033305

Ayala, H. (2003). Caso de estudio: Oro Verde Certificado. Programa Oro Verde Certificado. En Pequeña minería y minería artesanal en Iberoamérica (pp. 153-160). Río de Janeiro, Brasil: Corba.

Ayala-Camacho, G. K. y García-Samaniego, J. M. (2016). Percepción de la minería artesanal: La Paz, Amazonía de Ecuador. LIDER, 18(29), 32-48.

Azpur, J., Baca, E., Viale, C. y Monge, C. (2011). Extractivismo y transiciones hacia el post extractivismo en el Perú. En A. Alayza y E. Gudynas (eds.), Transiciones: post extractivismo y alternativas al extractivismo en el Perú (pp. 13-29). Lima, Perú: Cepes.

Bernex, N. (2008). La geografía de la percepción: una metodología de la proximidad para la sostenibilidad. Summa Humanitatis, 2(2), 1-20.

Deza, N. E. (1996). Mercury acumulation in fish from Madre de Dios, a goldmining area in the Amazon basin, Perú (Tesis de maestría). Recuperada de http://ir.library.oregonstate. edu/xmlui/bitstream/handle/1957/21063/Redacted_DezaArroyoNiltonEduardo. pdf?sequence $=1$

Dirección Regional de Salud (Diresa) (2010). Análisis de la situación de salud de Madre de Dios 2009. Recuperado de http://mddconsortium.org/wp-content/uploads/2014/11/ DIRESA-MDD-2009-Analisis-de-la-situacion-de-salud-de-Madre-de-Dios.pdf

Diringer, S. E., Feingold, B. J., Ortiz, E. J., Gallis, J. A., Araújo-Flores, J. M., Berky, A., Pan, W. A. y Hsu-Kim, H. (2015). River transport of mercury from artisanal and small-scale gold mining and risks for dietary mercury exposure in Madre de Dios, Peru. Environmental Science: Processes \& Impacts, 17(2), 478-487. https://doi.org/10.1039/ C4EM00567H

Dourojeanni, M. (1990). Amazonía: ¿qué hacer? Iquitos, Perú: Centro de Estudios Teológicos de la Amazonía. 
Dourojeanni, M., Barandiarán, A. y Dourojeanni, D. (2009). Amazonía peruana en 2021: explotación de recursos naturales e infraestructura: ¿qué está pasando?:qué es lo que significa para el futuro? Lima, Perú: Fundación Peruana para la Conservación de la Naturaleza.

Elmes, A., Yarlequé Ipanaqué, J. G., Rogan, J., Cuba, N. y Bebbington, A. (2014). Mapping licit and illicit mining activity in the Madre de Dios region of Peru. Remote Sensing Letters, 5(10), 882-891. https://doi.org/10.1080/2150704X.2014.973080

Fernández, L. E. y González, V. H. (26 de julio, 2019). Niveles del mercurio en peces de Madre de Dios [Diapositiva]. Recuperada de http://www.minam.gob.pe/mineriailegal/ wp-content/uploads/sites/43/2013/10/Carnegie-mercurio-Madre-de-Dios.pdf

García, H. (1998). Guía ambiental. Minería subterránea del carbón. Bogotá, Colombia: Ministerio del Medio Ambiente, Minercol. Recuperado de http://www.upme.gov.co/ guia_ambiental/carbon/gestion/guias/min_sub/indice.htm

Gobierno Regional de Madre de Dios e Instituto de Investigaciones de la Amazonía Peruana (Goremad-IIAP) (2008). Zonificación ecológica y económica del departamento de Madre de Dios: vegetación. Informe preliminar. Puerto Maldonado, Perú: Goremad, IIAP.

Gold, J. (1980). An introduction to behavioural geography. Oxford, Inglaterra: Oxford University Press.

Gutleb, A. C., Schenck, C. y Staib, E. (1997). Giant otter (Pteronura brasiliensis) at risk? Total mercury and methylmercury levels in fish and otter scats, Perú. Ambio, 26(8), 511-514.

Hacon, S. y Azevedo, F. (2006). Plan de Acción Regional para la Prevención y el Control de la Contaminación de Mercurio en los Ecosistemas Amazónicos. Brasilia, Brasil: Organización del Tratado de Cooperación Amazónica, Ministerio del Medio Ambiente.

Heemskerk, M. (2002). Livelihood decision making and environmental degradation: small-scale gold mining in the Suriname Amazon. Society \& Natural Resources, 15(4), 327-344. https://doi.org/10.1080/089419202753570819

Instituto de Investigaciones de la Amazonía Peruana y Ministerio del Ambiente (IIAPMinam) (2011). Mineria aurifera en Madre de Dios y contaminación con mercurio: una bomba de tiempo. Lima, Perú: IIAP-Minam.

Instituto Nacional de Estadística e Informática (2007). Censos Nacionales 2007: XI de Población y VI de Vivienda. Lima, Perú: Instituto Nacional de Estadística e Informática.

Junquera, C. (1997). El impacto del desarrollo en el paisaje y en las sociedades de la Amazonía: algunos ejemplos para reseñar la cuestión en el departamento peruano de Madre de Dios. Espacio y Desarrollo, 2(9), 87-99.

Kahhat, R., Parodi, E., Larrea-Gallegos, G., Mesta, C. y Vázquez-Rowe, I. (2019). Environmental impacts of the life cycle of alluvial gold mining in the Peruvian Amazon rainforest. Science of the Total Environment, 662, 940-951. https://doi.org/10.1016/ j.scitotenv.2019.01.246 
Kumar, A., Divoll, T. J., Ganguli, P. M., Trama, F. A. y Lamborg, C. H. (2018). Presence of artisanal gold mining predicts mercury bioaccumulation in five genera of bats (Chiroptera). Environmental Pollution, 236, 862-870. https://doi.org/10.1016/j. envpol.2018.01.109

La República (4 de junio, 2012). Ingeniero peruano inventa método para extraer oro sin dañar el ambiente. Recuperada de https://larepublica.pe/economia/636158-ingenieroperuano-inventa-metodo-para-extraer-oro-sin-danar-el-ambiente

Laverty, M. y Gibbs, J. (12 de febrero, 2010). Ecosystem loss and fragmentation. En American Museum of Natural History [Página web]. Recuperada de http://ncep.amnh. org/linc/linc_download.php?component_id=16

Medina, G. (2001). Mitigación del mercurio en la minería artesanal y pequeña minería aurifera del Perú. Lima, Perú: Gama. Recuperado de http://www.gama-peru.org/ jornada-hg/medina.pdf

Medina, G. (2007). Operaciones auríferas en Madre de Dios. Efectos ambientales. Minería \& medioambiente, 11, 8-11.

Medina, G., Arévalo, J. y Quea, F. (2007). Estudio de investigación de la minería ilegal en el Perú: repercusiones para el sector minero y el país. Recuperado de http://mddconsortium. org/wp-content/uploads/2014/11/IIMP-2007-Estudio-Mineria-IIlegal-en-el-Peru.pdf

Moreno-Brush, M., Portillo, A., Brändel, S. D., Storch, I., Tschapka, M. y Biester, H. (2018). Mercury concentrations in bats (Chiroptera) from a gold mining area in the Peruvian Amazon. Ecotoxicology, 27(1), 45-54. https://doi.org/10.1007/ s10646-017-1869-1

Mosquera, C., Chávez, M. L., Pachas, V. H. y Moschella, P. (2009). Estudio diagnóstico de la actividad minera artesanal en Madre de Dios. Lima, Perú: Fundación Conservación Internacional.

Murcia, C. (1995). Edge effects in fragmented forests: implications for conservation. TREE, 10(2), 58-62. https://doi.org/10.1016/S0169-5347(00)88977-6

Neisser, W. (1995). Estudio del efecto ambiental producido por el empleo del mercurio en la pequeña minería aurifera (Tesis de licenciatura). Pontificia Universidad Católica del Perú.

Nickerson, R. (2003). Psychology and environmental change. Mahwah, EE.UU.: Lawrence Erlbaum Associates.

Organización Mundial de la Salud (OMS) (2005). El mercurio en el sector de la salud. Documento de politica general. Recuperado de https://www.who.int/water_sanitation_health/medicalwaste/mercurio_es.pdf?ua=1

Programa de las Naciones Unidas para el Medio Ambiente. (2004). Regional awareness raising workshop on mercury pollution. Recuperado de http://www.eeaa.gov.eg/cmuic/ cmuic_pdfs/generalrep/HG_Buenos-Aires-proceedings2004.pdf 
Romero, M. K., Pachas, V. H., Zambrano, G. y Guarniz, Y. (2005). Formalización de la minería en pequeña escala en América Latina y el Caribe: un análisis de experiencias en el Perú. Lima, Perú: Cooperacción.

Salo, M., Hiedanpää, J., Karlsson, T., Ávila, L. C., Kotilainen, J., Jounela, P. y García, R. R. (2016). Local perspectives on the formalization of artisanal and small-scale mining in the Madre de Dios gold fields, Peru. The Extractive Industries and Society, 3(4), 1058-1066. https://doi.org/10.1016/j.exis.2016.10.001

Sánchez, L. E. (2000). Evaluación de impacto ambiental. II Curso Internacional de Aspectos Geológicos de Protección Ambiental. São Paulo, Brasil: Unesco. Recuperado de www. ingenieroambiental.com/4012/4evaluacion.pdf

Scott, G. (1981). Cambios en el perfil del suelo que resultan cuando la selva es convertida en Sabana, en Perú oriental. Geográfica, 93, 93-99.

Shrum, P. L. (2009). Analysis of mercury and lead in birds of prey from gold-mining areas of the Peruvian Amazon (Tesis de maestría). Clemson University, EE.UU.

Spiro, T. G. y Stigliani, W. M. (2004). Química medioambiental. Madrid, España: Pearson.

Swenson, J. J., Carter, C. E., Domec, J. C. y Delgado, C. I. (2011). Gold mining in the Peruvian Amazon: global prices, deforestation, and mercury imports. PloS one, 6(4). https://doi.org/10.1371/journal.pone.0018875

Tello, S. (2002). Situación actual de la pesca y la acuicultura en Madre de Dios. Recuperado de http://www.iiap.org.pe/Upload/Publicacion/PescaMDD.pdf

Tschirhart, C. (2011). La contaminación humana por mercurio: un sistema de determinantes socioespaciales a orillas del río Beni (Amazonía boliviana). Bulletin de l'Institut Français d'Études Andines, 40(3), 561-589. https://doi.org/10.4000/bifea.1329

Uhl, C. (1989). Disturbance and regeneration in Amazonia: lessons for sustainable landuse. Ecologist, 19(6), 235-240.

United Nations Economic Commission for Europe (1995). Consolidated environmental impact assessment checklist convention on environmental impact assessment in a transboundary context. Recuperado de https://www.unece.org/env/eia/resources/checklists.html

United States Environmental Protection Agency (Usepa) (2010). Mercury: health effects. Recuperado de http://www.epa.gov/mercury/effects.htm

Urteaga, P. (2003). La problemática minera y los pueblos indígenas en Madre de Dios, Perú. Lima, Perú: Federación Nativa del Río Madre de Dios y Afluentes. 